\title{
Erratum: II Brazilian Consensus on the use of human immunoglobulin in patients with primary immunodeficiencies
}

Erratum: II Consenso Brasileiro sobre o uso de imunoglobulina humana em pacientes com imunodeficiências primárias

\begin{abstract}
Ekaterini Simões Goudouris ${ }^{1}$, Almerinda Maria do Rego Silva ${ }^{2}$, Aluce Loureiro Ouricuri ${ }^{3}$, Anete Sevciovic Grumach ${ }^{4}$, Antonio Condino-Neto ${ }^{5}$, Beatriz Tavares Costa-Carvalho ${ }^{6}$, Carolina Cardoso de Mello Prando ${ }^{7}$, Cristina Maria Kokron ${ }^{8}$,

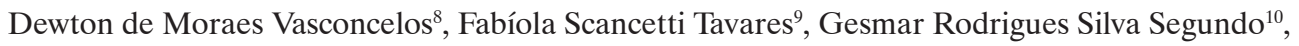
Irma Cecília Douglas Paes Barreto ${ }^{11}$, Mayra de Barros Dorna ${ }^{8}$, Myrthes Anna Maragna Toledo Barros ${ }^{8}$, Wilma Carvalho Neves Forte ${ }^{12}$; in name of Primary Immunodeficiency Group of the
\end{abstract}

Brazilian Society of Allergy and Immunology

In the manuscript "II Brazilian Consensus on the use of human immunoglobulin in patients with primary immunodeficiencies", DOI number: 10.1590/S1679-45082017AE3844, published at einstein (São Paulo). 2017; 15(1):1-16.

Page 6, stated: In this setting, it is possible to inject subcutaneous Ig every 21 to 28 days, just like intramuscular injections, with appropriate safety and good clinical results. ${ }^{(19)}$ It should be read: In this setting, it is possible to inject subcutaneous Ig every 21 to 28 days, just like intravenous injections, with appropriate safety and good clinical results. ${ }^{(19)}$

It the same article, page 8 , stated: In chart 8 , at the Osmolarity column, $32 \pm 4.5 \mathrm{mOsmI} / \mathrm{kg}$. It should be read: In chart 8 , at the Osmolarity column, $327 \pm 4.5 \mathrm{mOsmI} / \mathrm{kg}$.

\footnotetext{
${ }^{1}$ Universidade Federal do Rio de Janeiro, Rio de Janeiro, RJ, Brazil.

2 Universidade Federal de Pernambuco, Recife, PE, Brazil.

${ }^{3}$ Hospital Servidores do Estado do Rio de Janeiro, Rio de Janeiro, RJ, Brazil.

4 Faculdade de Medicina do ABC, Santo André, SP, Brazil.

${ }^{5}$ Universidade de São Paulo, São Paulo, SP, Brazil.

${ }^{6}$ Universidade Federal de São Paulo, São Paulo, SP, Brazil.

${ }^{7}$ Hospital Infantil Pequeno Príncipe, Curitiba, PR, Brazil.

${ }^{8}$ Hospital das Clínicas, Faculdade de Medicina, Universidade de São Paulo, São Paulo, SP, Brazil.

${ }^{9}$ Hospital de Base do Distrito Federal, Brasília, DF, Brazil.

${ }^{10}$ Universidade Federal de Uberlândia, Uberlândia, MG, Brazil.

${ }^{11}$ Centro Universitário do Estado do Pará, Belém, PA, Brazil.

12 Faculdade de Ciências Médicas, Santa Casa de São Paulo, São Paulo, SP, Brazil.

DOI: 10.1590/S1679-45082017AE3844E
} 